\title{
ANÁLISE DIALÓGICA DISCURSIVA: DESAFIOS E PERSPECTIVAS EM ESTUDOS SOBRE EDUCAÇÃO E CULTURA
}

\section{DIALOGICAL DISCOURSE ANALYSIS CHALLENGES AND PROSPESCTS FOR STUDIES ON EDUCATION AND CULTURE}

\author{
ANDRADE, Cláudia Cristina dos Santos ${ }^{1}$ \\ NEVES, Douglas Francisco de Mello ${ }^{2}$ \\ PRADOS, Juliana Maria Ferreira ${ }^{3}$ \\ BASTOS, Patrícia de Jesus ${ }^{4}$ \\ FREITAS, Tatiana Maia de ${ }^{5}$
}

\section{RESUMO}

As pesquisas em Ciências Humanas têm buscado perspectivas metodológicas que deem conta dos complexos processos subjetivos. A vertente discursiva tem se apresentado produtiva neste campo, ao iluminar a constituição dos discursos. Este trabalho apresenta reflexões sobre o potencial analítico da perspectiva discursiva, tal como define a ADD (Análise dialógica do discurso), a partir de sua utilização em quatro pesquisas cujo eixo comum é a investigação no campo do ensino que envolve as produções de sentido em face de elementos culturais. A análise das propostas de pesquisa exigiu um exercício exotópico sobre nosso fazer científico, revelando que a metodologia dialógica contribui para se pensar tanto os processos macrossociais de produção discursiva, quanto os processos microhistóricos, de desenvolvimento da linguagem. Os resultados apontam para a produtividade da proposta metodológica e suscitam questionamentos, próprios do inacabamento do conhecimento.

Palavras-chave: Perspectiva dialógica discursiva; Metodologia de pesquisa; Ensino; Cultura.

\section{ABSTRACT}

Research in Human Sciences has sought methodological perspectives that take into account complex subjective processes. The discursive dimension has been productive in this field, shedding light on the establishment of discourses. This article presents some reflections on the analytical potential of the discursive perspective, as defined by DDA (Dialogical Discourse Analysis), from its use in four researches that have in common the development of investigation in the field of teaching involving the production of meaning in the face of cultural elements. The analysis of the research proposals required an exotopic exercise on

\footnotetext{
${ }^{1}$ Professora do Programa de Pós Graduação de Ensino de Educação Básica - PPGEB/UERJ.

2 Mestrando do Programa de Pós Graduação de Ensino de Educação Básica - PPGEB/UERJ.

${ }^{3}$ Mestranda do Programa de Pós Graduação de Ensino de Educação Básica - PPGEB/UERJ.

${ }^{4}$ Mestre em Ensino pelo Programa de Pós Graduação de Ensino de Educação Básica - PPGEB/UERJ.

${ }^{5}$ Mestranda do Programa de Pós Graduação de Ensino de Educação Básica - PPGEB/UERJ.
} 
our own scientific work, showing that the dialogical methodology contributes to reflecting upon both the macrosocial processes of discursive production as well as the micro-historical processes of language development. The results point to the productivity of that methodological proposal and evoke much questioning, unique to the incompleteness of knowledge.

KeYwORDS: Discursive dialogic perspective; Research methodology; Teaching; Culture.

\section{INTRODUÇÃo}

Como construímos nossa compreensão de mundo? Como "escolhemos" nossas tendências ideológicas? Quais as interfaces entre as produções sócio-culturais e o desenvolvimento da linguagem? Tais questões perpassam variados estudos no campo da linguagem e exigem um aparato metodológico que permita abarcar processos subjetivos de construção de sentidos.

Para o campo do ensino, as investigações sobre esses processos contribuem com a compreensão das relações discursivas $e$, em consequência, com 0 desenvolvimento de estratégias metodológicas que levem em conta os diferentes movimentos de interpretação e produção de enunciados, entrelaçados com as muitas vozes que habitam o ambiente escolar.

O presente trabalho se debruça sobre um quadro epistêmico que tem sido usado em variados estudos linguísticos e das Ciências Humanas de forma geral, advindo das proposições teóricas do Círculo de Bakhtin. Nesse paradigma consideram-se os dados subjetivos, levando-se em conta a complexidade do humano em sua intrínseca relação com a história. Parte-se do princípio de que os sentidos produzidos carregam a historicidade em que estamos imersos que, dialeticamente, passam a pertencer a novas possibilidades de olhar. Nessa relação, a pesquisa precisa compreender a necessária relação do pesquisador com o Outro, não só o pesquisado, mas também com o Outro que o constitui.

Geraldi (2003, p.43) extrai da obra de Bakhtin "conceitos formulados na análise estética para extrair consequências éticas". Percorre os conceitos de diálogo e de alteridade para concluir que somos seres por-vir, inacabados, e só existimos na interação com o Outro. Geraldi ressalta que

No mundo dos acontecimentos da vida, campo próprio do ato ético, estamos sempre inacabados, porque definimos o presente como conseqüência de um passado que construiu o pré-dado e pela memória do futuro com que se definem as escolhas no horizonte das possibilidades. Nosso acabamento atende a uma necessidade estética de totalidade, e esta somente nos é dada pelo outro, como criação e não como solução. A vida, concebida como acontecimento ético aberto, não comporta acabamento e, portanto, solução (GERALDI, 2003, p.42). 
A análise de Geraldi apresenta a trajetória reflexiva de Bakhtin, ao extrair do campo estético elementos que compõem uma ética na pesquisa, posta no compromisso do pesquisador em considerar a complexidade humana.

Essa proposição metodológica se respalda, também, em reflexões epistemológicas sobre o saber científico. Santos (1989) propõe superar a distância entre os saberes empírico e científico, repensando o papel da ciência hoje e buscando compreender como seria um novo paradigma científico. Para o autor, o atual paradigma não dá conta de forma eficaz dos objetos de estudo porque não considera a subjetividade inerente, e nem tem contribuído de maneira competente para a melhoria da qualidade de vida das pessoas no mundo. É preciso, então, buscar novas formas de lidar com o conhecimento, inclusive rompendo com a dicotomia sujeito/objeto, já que esta relação se daria num continuum. O olhar do sujeito interfere no objeto. Santos (1989) apresenta a possibilidade de uma segunda ruptura epistemológica, em que o saber produzido pela ciência se encontraria com o senso comum, levando em conta outros conhecimentos e, portanto, gerando um novo saber que possa ser apropriado por todos, na forma de um senso comum esclarecido.

A reflexão sobre a proposta metodológica dialógica discursiva se faz nesse artigo pela discussão de seus conceitos básicos para, em seguir, analisar sua aplicabilidade em quatro estudos, que apresentam como eixo comum 0 desenvolvimento de investigações no campo do ensino que envolvem as produções de sentido em face dos elementos culturais e buscam, em suas pesquisas, trazer o ensino para o centro de suas análises, o que reforça a premência do olhar para os elementos micro e macrossociais que estão em jogo nas relações humanas.

Os discursos produzidos e entrelaçados nos estudos analisados são pensados sob a luz da Análise Dialógica do Discurso, proposição metodológica que pensa a pesquisa tendo como base os conceitos advindos do Círculo de Bakhtin. Utilizamos, especialmente, os textos de Amorim (2006), Paula (2013) e Rohling (2014).

\section{A PERSPECTIVA DIALÓGICA DISCURSIVA: CONCEITOS BÁSICOS}

A perspectiva dialógica discursiva traz como um de seus pilares a concepção de que a construção subjetiva se forma em interação com complexo social, com base no pensamento de Bakhtin $(1987,1992)$ e que, como afirma Wersch (1991), fundamenta a ideia de que a formação da mente carrega componentes construídos socialmente. Os conceitos de diálogo e de alteridade são importantes para a compreensão de como as mensagens são compartilhadas e como sua circulação faz parte da formação subjetiva, de forma a construir significados relativamente estáveis que compõem uma ideologia do cotidiano. 
A linguagem é entendida como constitutiva do sujeito e meio para a construção social dos sentidos, pensada como elemento marcado pela ideologia e dialeticamente, desvelador desta. Sabemos que estão presentes na formação do signo imposições, verdades cristalizadas por grupos sociais, que podem ou não ser apropriadas pelo sujeito, pois "a personalidade que se exprime, apreendida, por assim dizer, do interior, revela-se um produto total da inter-relação social" (BAKHTIN, 1997, p.117). Para o autor, os sistemas ideológicos se constroem:

a partir da ideologia do cotidiano, [e] exercem, por sua vez sobre esta, em retorno, uma forte influência e dão assim normalmente o tom a essa ideologia. Mas, ao mesmo tempo, esses produtos ideológicos constituídos conservam constantemente um elo orgânico vivo com a ideologia do cotidiano; alimentam-se de sua seiva, pois, fora dela, morrem, assim como morrem, por exemplo, a obra literária acabada ou a ideia cognitiva se não são submetidas a uma avaliação crítica viva (BAKHTIN, 1997, p. 119).

A grande contribuição de Bakhtin se faz na medida em que se assegura que a atividade individual não existe como tal, pois a atividade mental do eu só existe em relação com a atividade mental do nós, que, por sua vez, permite diferentes graus e diferentes tipos de modelagem ideológica. Quanto mais organizada a atividade social, mais consistente e definida é a atividade mental.

Nessa perspectiva, pesquisador e sujeitos pesquisados são produtores de textos/ discursos, o que, segundo Amorim (2006, p. 98), "confere às Ciências Humanas um caráter dialógico". No campo do ensino contribui para a compreensão da formação da mente e, assim, dos processos de aprendizagem. Como afirma Wersch (1991), os conceitos de voz, diálogo, gêneros textuais e linguagens sociais sustentam a ideia de que a formação da mente carrega componentes construídos socialmente, explicitando como as mensagens são compartilhadas e como sua circulação faz parte da formação subjetiva, construindo significados relativamente estáveis que compõem uma ideologia do cotidiano.

Constitui-se, nessa perspectiva metodológica, a percepção de como os processos intrassubjetivos se conjugam com os intersubjetivos relacionados a condições macrossociais, de forma a não emudecer o texto produzido pelos sujeitos da pesquisa, considerando na análise as condições de enunciação e de circulação que lhe são próprias (AMORIM, 2006).

Tal forma de se fazer ciência se opõe frontalmente ao modelo objetivante que marca a proposição positivista, ao definir somente duas posições de interlocução: o pesquisador, de um lado, neutro e sem voz; e o sujeito pesquisado, de outro, analisado a partir de categorias pré-definidas. O pesquisador, na perspectiva discursiva, assume sua intervenção na obtenção e análise dos dados. Aí reside o 
componente ético da pesquisa: ao se assumir parte, 0 pesquisador busca compreender que elementos de sua subjetividade estão presentes nos resultados da pesquisa.

Nesse sentido, Souza e Albuquerque (2012, p. 112), afirmam que "o pesquisador se indaga sobre a especificidade do conhecimento que é produzido de forma compartilhada, na tensão entre o eu e o outro, por meio de uma cumplicidade consentida entre ambos".

A partir dessas proposições teóricas, já encontramos autores que organizam em torno da Análise Dialógica do Discurso (ADD), uma proposta metodológica que congrega conceitos advindos dos estudos linguísticos e os construtos bakhtinianos. Paula (2013) afirma ser possível falar, no Brasil, de uma perspectiva dialógica que se filia a uma tradição analítica posta entre a linguística e a translinguística. Atribui esta peculiaridade ao percurso histórico que os estudos linguísticos tiveram no Brasil, em que várias linhas da chamada Análise do Discurso (crítica, semiótica, AD francesa, teoria da enunciação de Benveniste) dialogaram, possibilitando que se possa falar, aqui, de ADs. Esse diálogo criou um terreno fértil para a aceitação das noções advindas do Círculo de Bakhtin (conjunto de textos produzidos por Bakhtin e seus seguidores, muitas vezes com o uso de pseudônimos), em especial, diálogo, sujeito, signo ideológico e exotopia. A autora analisa historicamente as condições de produção de uma dada leitura de Bakhtin que propicia o que Brait chama de Análise Dialógica do Discurso.

O quadro epistêmico gerado pela ADD não se constitui de procedimentos inflexíveis, mas podem ser observados parâmetros, como os descritos por Rohling (2014, p.50):

- O estudo da esfera de atividade humana, em que se dão as interações discursivas em foco;

- A descrição dos papéis assumidos pelos participantes da interação discursiva, analisando as relações simétricas/assimétricas entre os interlocutores na produção de discurso;

- O estudo do cronotopo (o espaço-tempo discursivo) dos enunciados;

- O estudo do horizonte temático-valorativo dos enunciados;

- A análise das relações dialógicas que apontam para a presença de assimilação de discursos já-ditos e discursos prefigurados, discursos bivocais, apagamentos de sentidos, contraposições, enquadramentos, reenunciação de discursos e reacentuações de discursos.

Por outro lado, "as categorias emergem das relativas regularidades dos dados, que são observadas/apreendidas no percurso da pesquisa" (ROHLING, 2014,p.14). 
Assim, cada estudo constrói suas próprias categorias, "pois o dado é sempre o discurso concreto e único proferido em um determinado espaço e tempo e por determinados interlocutores" (idem, ibidem).

Esses pressupostos estão sendo discutidos e desenvolvidos em quatro estudos realizados por componentes de um grupo de pesquisa, cuja preocupação central é a relação entre a cultura e educação. $O$ presente artigo resulta de um exercício exotópico, em que buscamos analisar a pertinência e produtividade da perspectiva dialógica discursiva para os objetivos das pesquisas. Dos quatro estudos apresentados, somente um se encontra finalizado.

\section{REFLETINDO SOBRE A ADD EM ESTUDOS SOBRE EDUCAÇÃO E CULTURA}

Os trabalhos aqui analisados nascem das investigações de um mesmo grupo de pesquisa, e possuem como eixo comum o desenvolvimento de estudos no campo do ensino que envolvem as produções de sentido em face de elementos culturais. Especificamente, as pesquisas buscam compreender: 1) ações que alimentem os processos de constituição dos sentidos; 2) a compreensão dos processos de comunicação em crianças com deficiência ou desvio no desenvolvimento da linguagem; 3) a identificação de potencialidades no trabalho da escola com o cinema; observados os discursos historicamente constituídos; 4) a relação entre os discursos produzidos historicamente em torno dos contos de fadas e os sentidos produzidos pelas crianças.

O grupo busca analisar o papel da linguagem no desenvolvimento humano, e, por consequência, sua relação com os processos de ensino-aprendizagem. Os trabalhos aqui expostos lidam com essa questão a partir de diferentes objetos de pesquisa. Uma primeira análise dos objetos sugeriu a organização dos estudos em dois eixos: os que se preocupam com o desenvolvimento da linguagem por crianças em processos inclusivos e os que lidam com as relações dialógicas entre sujeitos e os discursos sociais.

\section{A CONSTRUÇÃO MICRO-HISTÓRICA DO DISCURSO: DESAFIOS E PERSPECTIVAS EM PROCESSOS INCLUSIVOS}

Sob o eixo da construção micro-histórica do discurso, as pesquisas "Os desafios e as tecnologias aplicadas para a aquisição de código linguístico em crianças com surdez imersas em ambiente ouvinte: Uso de Novas Tecnologias em Estudo de Caso" e "A linguagem expressa pela criança com Transtorno do Espectro Autista (TEA) em ambiente escolar", buscam compreender a construção da linguagem em crianças que possuem desvio nos processos de comunicação verbal, sob a perspectiva discursiva. $O$ grande desafio dos estudos é pensar o funcionamento da linguagem desses sujeitos a partir de um referencial teórico sem lastro consistente 
na literatura científica sobre os processos inclusivos. Ambos os trabalhos se situam no ambiente escolar, em escolas regulares, tendo em vista a Política Nacional de Educação Especial na Perspectiva da Educação Inclusiva, que indica que os alunos com deficiência, transtornos globais do desenvolvimento e altas habilidades/superdotação tem direito a acesso às escolas regulares com igualdade de oportunidades (Brasil, 2010).

As discussões travadas no grupo de pesquisa levaram a uma premissa inicial: a linguagem que a criança autista e a criança surda produzem é uma contra-palavra, através da qual estes tentam compreender, significar e ressignificar as palavras do mundo que ouvem e têm acesso.

Sabemos que existe uma multiplicidade inumerável e ilimitada de sentidos produzidos e que estes assim o são por serem constituídos contexto histórico cultural que estamos inseridos. Nesse sentido, indagamos sobre as interfaces desses processos com os elementos culturais do mundo: quais são as intervenções humanas e tecnológicas que provocam as expressões nessas crianças?

A partir das contribuições de Bakhtin $(1992,1997)$ compreendemos a natureza ideológica do signo, carregado de concepções tecidas pelas relações sociais. Na construção do signo no interior do sujeito com um desvio de apropriação na linguagem, seja este desvio por prejuízo sensorial, ou social, ou da ordem do desenvolvimento, queremos identificar as relações que o permeiam, de forma a contribuir para a compreensão de seus processos de aprendizagem, propondo intervenções pedagógicas.

$\mathrm{Na}$ pesquisa que investiga a construção de conhecimentos de uma criança com surdez inserida em família ouvinte, a principal preocupação é a aprendizagem dos códigos linguísticos e as possibilidades do uso da tecnologia nos processos de ensino.

Neste campo, há um fator preponderante, que é o bilinguismo, proposta fundamental para o ensino das crianças surdas. O Decreto no 5626, de 2005 regulamenta a Lei no 10436 de 2002 que dispõe sobre a LIBRAS e sua ampla implementação na formação de professores e no acesso da pessoa com surdez. Atualmente fomenta-se a inclusão deste aluno desde os primeiros anos de sua infância com uma proposta bilíngue em que os dois idiomas, Língua Portuguesa escrita e LIBRAS, não dicotomizam, mas coexistem no espaço escolar. Porém, ainda há entraves neste processo de escolarização, em especial o pouco acesso de professores a LIBRAS.

Esse fato se agrava quando a pessoa com surdez oriunda de família ouvinte, que em muitos casos, desconhece maneira eficaz de interagir e trocar não só no ambiente escolar, mas na família e sociedade. Embora a comunicação caseira e familiar, nata entre família-filho, seja oral e gestual, não sempre é fomentado o crescimento linguístico do aluno, seja por vertente oralista, seja incentivando uma 
espécie de gestos informais ou outro código, sendo um jogo mímico onde um tenta se comunicar com o outro, não trazendo a completude do potencial comunicativo que não se limita a entender sins e nãos, gostar e não gostar, querer e não querer, mas de expressar na sua plenitude os pensamentos, informações, instruções, sentimentos e nuances da mente.

Baseando-se na perspectiva discursiva, sabemos que a pessoa, em seu discurso, não se constitui sozinha, mas no/com o outro. Logo não existe o eulinguagem, uma linguagem própria que funcione no interior do sujeito, sem uso e relevância para sua comunicação com o mundo exterior. Como esta pessoa com surdez se constitui e/ou constitui-se nesse nós-linguagem, se está sensorialmente privado desta comunicação e sua troca com os seus pares é inferior em valor comunicativo?

Para Bakhtin (1997), a língua/linguagem é construída dialogicamente e se constitui na troca com o outro, sendo o sujeito fundamental para a constituição do nós-linguagem. $\mathrm{E}$ no processo ensino-aprendizagem o professor que recebe esse sujeito na sua aula não é, ainda, instruído a contento para trabalhar a construção da língua/linguagem deste público, que não apresenta nenhum empecilho neurológico, mas comunicacional.

\begin{abstract}
Essas pessoas enfrentam inúmeros entraves para participarem da educação escolar, decorrentes da especificidade do limite que a perda da audição provoca e da forma como se estruturam as propostas educacionais das escolas. Muitos alunos com surdez podem ser prejudicados pela falta de estímulos adequados ao seu potencial cognitivo, sócio-afetivo, lingüístico e político-cultural e ter perdas consideráveis no desenvolvimento da aprendizagem, ficando aquém dos demais colegas de escola (BRASIL, 2007. p 13).
\end{abstract}

A pesquisa, em andamento, traz como uma de suas hipóteses a necessidade do fomento de diferentes gêneros discursivos, em que se valorize o uso e função social. Bakhtin (1997, p. 132) afirma que "o tema da enunciação é determinado não só pelas formas linguísticas que entram na composição (as palavras, as entonações, as formas morfológicas ou sintáticas, os sons, as entonações), mas igualmente pelos elementos não verbais da situação". Assim entendemos que mesmo a comunicação da pessoa com surdez sendo gesto-visual ou oro-facial, está banhada no discurso. A mobilização de diferentes gêneros ativa diferentes discursos, constituindo possibilidade expressiva e compreensiva. Acreditamos que a inserção de recursos tecnológicos contribui para consolidar este ponto comum, dirimir barreiras, proporcionando recursos para as pessoas que apresentam defasagem comunicacional ou não eficiente, afetando sua capacidade oral e escrita e 


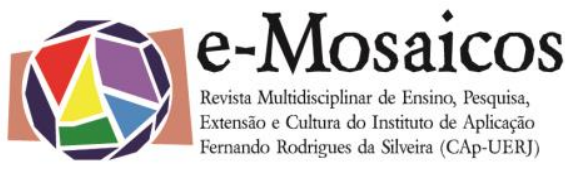

DOI: $10.12957 /$ e-mosaicos.2017.30257

construindo um relacionamento interativo e a experiência dialógica, fatores pertencentes a um processo de inclusão eficaz.

No segundo trabalho, a pesquisadora aborda os atos comunicativos de uma criança com TEA, e também levanta questões: como é a linguagem que a criança autista constrói e de que maneira o Outro (VIGOTSKY, 1987) se insere na produção de linguagem dessa criança?

Partindo do princípio que a presença do Outro é fundamental na produção da linguagem humana, Vigotsky (1997) afirma que nos tornamos humanos a partir da nossa relação com outro humano. Seguindo esse caminho, o objetivo do trabalho é tentar compreender os sentidos produzidos nos atos comunicativos expressos pela criança com autismo. Ainda em Vigotsky (1997), compreendemos que a função primordial da fala é a comunicação, o intercâmbio social, contudo, uma das características do TEA é justamente o desvio no desenvolvimento da linguagem. Observa-se em indivíduos com TEA o uso da ecolalia, ou seja, a repetição mecânica de palavras e até mesmo frases que ouve. Estudos de Saad, Goldfeld (2009), Fernandes (2011) apontam a ecolalia como uma tentativa de manter contato social, quando o indivíduo é confrontado com uma linguagem além de suas competências lingüísticas. Nesse sentido, o grande desafio posto neste trabalho será identificar os marcadores sociais nos enunciados desta criança, bem como analisar se e em que medida há dialogicidade no discurso apresentado no universo que habita uma criança autista. Para tanto, a pesquisadora apoia-se nas teorias do Desenvolvimento de Vigotsky (1987) e o conceito de linguagem definido por Bakhtin (1997, 1992).

Esse projeto de pesquisa se justifica pela necessidade de produzir conhecimento científico partindo do ambiente escolar, no âmbito da linguagem. $O$ estudo do estado da arte realizado pela pesquisadora não revela pesquisas sobre os atos comunicativos focalizando as formas de produção de discurso pelas crianças autistas em ambiente puramente escolar. Revelou sim, pesquisas sobre 0 tema realizadas por profissionais da área da saúde e sua maioria em ambientes terapêuticos. Será realizada a observação da linguagem produzida e desenvolvida pela criança com TEA no cotidiano escolar, com o objetivo identificar as diferentes formas de expressão, compreendendo-as no contexto das funções comunicativas (FERNANDES, 2011). Como os sentidos são produzidos, como a criança compreende o que ouve e como ela pensa no que vai falar. Como se dá a comunicação e como esta é expressa, é possível a escolar colaborar no desenvolvimento da comunicação de estudantes com TEA em ambiente escolar?

Ambas as pesquisas apresentam desafios importantes para a compreensão dos processos de desenvolvimento da linguagem. Suas hipóteses vislumbram um mundo nem sempre perceptível, que se esconde no interior do sujeito pelas barreiras comunicacionais. A perspectiva discursiva traz a necessidade de se revelar este mundo, buscando o universo de significação oculto por uma aparente mudez. 


\section{DISCURSOS SOCIAIS: CONSTRUÇÃO MACRO-HISTÓRICA E PRODUÇÃO DE SENTIDOS}

As pesquisas "Potencialidades das experiências de cinema na educação básica" e "Como não adormecer para a discussão da identidade de gênero: uma análise discursiva sobre o conto A Bela Adormecida e a obra cinematográfica Malévola à luz do melodrama" se imbricam a partir da constituição dos discursos sociais. Ambas buscam estruturar como esses discursos surgem nos campos macros e microssociais. De um lado, o estudo do cinema e o modo como, na escola, vários enunciados vão sendo construídos e reverberados a partir de situações políticas, sociais e acadêmicas. De outro, os contos de fadas sendo analisados do ponto de vista dos papéis já socialmente formatados e do ponto de vista de uma nova geração que se vê agora leitora desses clássicos.

Nesse último, há primeiro um estudo sobre os discursos contidos nos contos de fadas, que acabam sendo os macro discursos sociais sobre determinados papéis que são exercidos na sociedade, em especial pelas mulheres. Posteriormente, há uma tentativa de entender como as crianças, atuais leitoras desses discursos, enxergam esses papéis e, a partir disso, quais são os micro discursos que elas proferem sobre eles. A especificidade desse trabalho reside na busca de interseções que rompem com paradigmas já estabelecidos, a partir de atividades com base no conto A Bela Adormecida e no filme Malévola.

Essa pesquisa aborda o elemento fundamental dos contos de fadas na formação da criança, analisando a produção de sentidos em uma perspectiva discursiva. A partir da experiência com oficinas de Melodrama que problematizam a questão do gênero no conto A Bela Adormecida e na obra cinematográfica Malévola, serão observadas mutações significativas e/ou permanências de sentido. Compreende-se, na pesquisa, o conto na perspectiva trazida por Calvino (2004) e Machado (2002), que ressaltam a importância dos contos para a formação humana, seja da criança ou para reformulação de pensamentos de um adulto que revisita um clássico.

Para a autora, a partir do pensamento de Calvino (2004), os clássicos sempre se revelam novos e inéditos, e exercem grande poder de influência sobre aqueles que o leem e até mesmo sobre aqueles que apenas ouvem ou assistem. Dialogicamente, os leitores acrescentam ao que contam elementos de sua vivência, como se observa no dito popular: Quem conta um conto, aumenta um ponto. A atividade humana, compreendida como atividade social, compõe, pelos séculos, versões infindas de contos e recontos e é por esta mutação oral e por toda a beleza de se acrescentar novos pontos de vista, personagens, ou até mesmo acontecimentos aos contos antigos, que hoje conhecemos certas histórias como elas são. 


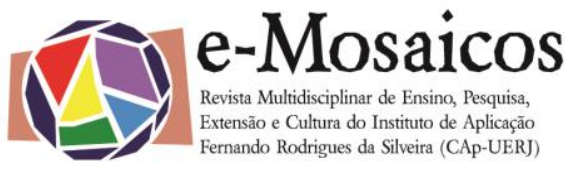

DOI: $10.12957 /$ e-mosaicos.2017.30257

Os contos, em sua origem, traziam, na verdade, histórias muito obscuras e algumas vezes macabras. Nestes tempos remotos não havia uma preocupação com o que hoje conhecemos por Infância. De Basile aos Irmãos Grimm, algumas modificações foram empregadas, também influenciados por um ideário cristão, visando abrandar os enredos a fim de que as crianças pudessem tirar proveito das histórias. Assim, a Disney em suas adaptações, romantiza os contos para conquistar o público infantil, especialmente o feminino.

O ideal romântico que vem a ser questionado na nova versão do conto, no filme homônimo da antagonista, Malévola, é ponto de partida para a pesquisa. Dada a importância dos Clássicos para a formação do imaginário infantil, e também como iniciação à literatura, percebe-se que as adaptações ainda precisam ser mais incisivas para ganhar a atenção das crianças desta geração, mesmo sendo os clássicos atemporais e universais. Em uma época em que as mulheres estão conquistando seu espaço, empoderando-se e tomando seu lugar de luta, há que se apresentar a infância algo que seja mais verossimilhante. Isso quer dizer que devemos trabalhar com o imaginário de forma mais crítica fazendo-os refletir sobre tais representações. O questionamento então é, as garotas de hoje, conseguem se enxergar nesses contos?

Em "Potencialidades das experiências de cinema na educação básica", pesquisa já finalizada, a base metodológica a partir de Bakhtin (2006) guiou a compreensão do caráter social do discurso. Desta forma, a primeira preocupação foi explicitar como a presença do cinema na educação vem sendo pensada desde a sua chegada ao Brasil. A partir disso, pode-se perceber três macro discursos sobre a questão, quais sejam: o cinema ocupando o espaço escolar como ideologia, o cinema sendo utilizado como instrumento e o cinema visto como arte. Com isso, chega-se à visualização de três instantâneos. A ideia de instantâneos remonta a "momentos que após o clique fotográfico parecem congelados no tempo" (BASTOS, 2016, p.43). Eles representam uma concepção hegemônica em determinado tempo histórico.

O primeiro instantâneo diz respeito ao período em que o Instituto Nacional de Cinema Educativo atuou, que vai de 1936 até 1967. Com o fim do Instituto, há o surgimento de um segundo instantâneo, a partir dos anos 1970. Sua principal característica é a tendência tecnicista, situando o filme como instrumento tecnológico a ser utilizado pelos professores em suas aulas. Essa visão domina o cenário até o início dos anos 2000, quando projetos audiovisuais, cuja visão sobre o cinema se dá a partir de seu caráter artístico, começam a atuar. Em comum, esses projetos têm a ideia de que é possível criar dentro da escola, tanto no ver quanto no fazer.

Após os discursos macrossociais serem entendidos, a busca foi compreender como professores de escolas de cinema dentro de escolas de educação básica pensavam a presença do cinema dentro deste ambiente. A partir dos micro discursos desses entrevistados, nasceram as análises das potencialidades que se revelaram. Assim, a pesquisa faz uma análise dos discursos sobre a presença do cinema no 
trabalho pedagógico e do impacto que ela teve no que é considerado cinema na escola atualmente.

\section{CONSIDERAÇõES FINAIS}

As discussões acerca dos trabalhos nos leva a concluir que, nesta perspectiva, é possível abarcar processos subjetivos, considerando sua intrínseca relação com o complexo social. A escolha do pensamento de Bakhtin como eixo metodológico permite a afirmação de que a ADD enfatiza presença da alteridade própria da linguagem, que reforça o caráter dialógico travado entre os temas, trazendo para as pesquisas uma "compreensão ativa e a presença do outro como constituintes do discurso" (ROHLING, 2014, p.45). Mesmo em andamento, as pesquisas apontam para o aprofundamento da compreensão das relações postas na linguagem, e como os discursos constituídos socialmente impactam a produção individual de linguagem, com diferenças nos focos. O primeiro trabalho propõe uma estratégia pedagógica para o desenvolvimento da linguagem na sua interface com a tecnologia, enquanto o segundo trabalho busca compreender a construção dos discursos sociais sobre a presença do cinema na escola. Já o terceiro e o quarto se aproximam dos sujeitos pesquisados, com a intenção de desvelar, neles, aspectos singulares em diálogo com alguma produção social.

Assim, pensa-se a linguagem como produção humana que se faz na relação com o Outro, portanto, constitutiva dos sujeitos e que, ao revés, a constituem, sempre em luta ideológica.

\section{REFERÊNCIAS BIBLIOGRÁFICAS}

ALBUQUERQUE, Elaine Deccache Porto, SOUZA, Solange Jobim. A pesquisa em ciências humanas: uma leitura bakhtiniana. Bakhtiniana, São Paulo, 7 (2): 109-122, Jul./Dez. 2012.

AMORIM, M. "Cronótopo e exotopia". In: BRAIT, B. (Org.). Bakhtin - outros conceitos-chave. São Paulo: Contexto, 2006.

BAKHTIN, Mikhail (V.N. Volochinov). Marxismo e Filosofia da Linguagem. São Paulo, Editora Hucitec, 1997.

. Estética da criação verbal. São Paulo: Martins Fontes,1992.

BASTOS, Patricia. Potencialidades das experiências de cinema na escola de Educação Básica. Dissertação (Mestrado). Programa de Pós-Graduação de Ensino em Educação Básica do Instituto de Aplicação da Universidade do Estado do Rio de Janeiro. Rio de Janeiro: UERJ, 2016. 
BRASIL. Casa Civil. Presidência da República. Subchefia Para Assuntos Jurídicos. Lei no 12.764, de 27 de dezembro de 2012.: LEI BERENICE PIANA. Brasília DF: Presidência da República, 2012. 3 p. Disponível em <HTTP:BRASIL, MEC/SEESP. Formação Continuada a Distância de Professores para o Atendimento Educacional Especializado: Pessoa com Surdez. Brasília, 2007.

Fernandes FDM. Pragmática. In: Andrade CRF, Befi-Lopes DM, Fernandes FDM, Wertzner HF. ABFW: teste de linguagem infantil nas áreas de fonologia, vocabulário, fluência e pragmática. 2a ed. Carapicuíba: 2011.

CALVINO, Ítalo. Por que ler os clássicos. 2 ed. São Paulo: Companhia das Letras, 2004. Trad. Nilson Moulin.

MACHADO, A. M. Como e porque ler os clássicos universais desde cedo. Rio de Janeiro: Objetiva, 2002.

PAULA, Luciane. Círculo de Bakhtin: uma Análise Dialógica de Discurso. In: Revista de Estudos da Linguagem: Belo Horizonte, v.21, n.1, p.239-258, jan/jun. 2013.

ROHLING, Nívea. A pesquisa qualitativa e análise dialógica do discurso: caminhos possíveis. In: Cadernos de Linguagem e Sociedade, 15(2), p.44-60. 2014.

SANTOS, Boaventura S. Introdução a uma Ciência Pós-Moderna. Porto: Afrontamento, 1989 (6ª edição). Também publicado no Brasil, São Paulo: Graal (3a edição).

SOUZA, Solange Jobim; ALBUQUERQUE, Elaine Daccache Porto. A pesquisa em Ciências Humanas: uma leitura bakhtiniana. In: Revista Estudos Discurso. São Paulo. v. 7, n. 2. Dezembro/2012. Disponível em: http://www.scielo.br/scielo.php?script=sci _arttext\&pid=S2176-45732012000200008\&Ing=em\&nrm=iso . Acesso em 9 de julho de 2017.

VYGOTSKY, L. S.. Pensamento e Linguagem. São Paulo: Martins Fontes, 1987.

WERTSH, James V. Voces de la mente. Un enfoque sociocultural para el estudio de la acción mediada. Madri: Ed. Aprendizage Visor, 1991. 